\title{
Théologiques
}

\section{Thèses et mémoires acceptés à la Faculté de théologie de l’Université de Montréal en 1992}

Volume 1, numéro 1, mars 1993

Théologie et sciences humaines en contexte universitaire

URI : https://id.erudit.org/iderudit/602386ar

DOI : https://doi.org/10.7202/602386ar

Aller au sommaire du numéro

Éditeur(s)

Faculté de théologie de l'Université de Montréal

ISSN

1188-7109 (imprimé)

1492-1413 (numérique)

Découvrir la revue

Citer ce document

(1993). Thèses et mémoires acceptés à la Faculté de théologie de l'Université de Montréal en 1992. Théologiques, 1(1), 139-141. https://doi.org/10.7202/602386ar d'utilisation que vous pouvez consulter en ligne.

https://apropos.erudit.org/fr/usagers/politique-dutilisation/ 


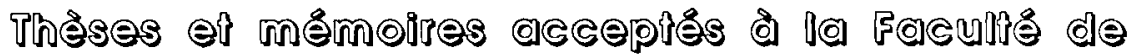

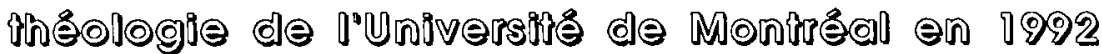

\section{Thèses}

JACQUES, Robert

$\mathrm{Ph}$. D. Th.- études théol. Jean-C. PETIT(dir.)

LEFEBVRE, Solange

$\mathrm{Ph}$. D. Th.- études théol. Maurice BOUTIN (dir.) Joseph HOFBECK (co. dir)
Dieu livré au pardon des humains exploration théologique d'une expression contemporaine de l'expérience religieuse à la lumière de la poétique du récit de $\mathrm{P}$. Ricoeur

Sécularité et sécularisation. Questions actuelles des instituts séculiers

\section{Mémoires}

ANTANGANA, Dieudonné Magloire

M. A. Th. - études past. André CHARRON (dir.)

BIGRAS, Diane

M. A. Th. - études théol. Gilles CHAUSSÉ (dir.)

BLEE, Fabrice

M.A. Th. - études théol. Richard BERGERON (dir.)
La coresponsabilité clercs-laïcs en paroisse au Cameroun: lieu de crise et d'exercice commun

Jeanne Mance, une fascination des historiens

L'enseignement sur la mort de Bokar Rimpotche et la théologie de la mort de Karl Rahner. Pour un dialogue inter-religieux 
BOYER, François

M.A. Th. - études past.

Jean-M. GAUTHIER (dir.)

CLICHE, Réal

M.A. Th. - études bibl.

André MYRE (dir.)

CHOQUET, Louise

M.A. Th. - études past.

Michel CAMPBELL (dir.)

DENIS, Alain

M.A. Th. - études théol.

Guy LAPOINTE (dir.)

JULIEN, Éliane

M.A. Th. - études bibl.

Jean-L. D'ARAGON (dir.)

LEBRUN, Lise

M.A. Th. - études past. Jacques GRAND'MAISON (dir.)

LÉGER, Louis

M.A. Th. - études théol.

Guy DURAND (dir.)

LEGROS, Micheline

M.A. Th. - études past.

Jean-M. GAUTHIER (dir.)

MAILLOUX, Mario

M.A. Th. - études past.

Jean-M. GAUTHIER (dir.)

MÉNARD, Jacques

M.A. Th. - études théol.

Guy DURAND (dir.)
De la certitude au risque. Pour une pastorale baptismale dialogale

Une approche expérientielle de l'Esprit Saint à partir de l'héritage biblique pour les enseignantes et les enseignants du primaire

Souffrance et pèlerinage à l'Oratoire Saint-Joseph. Essai de pastorale

Le concept de transsubstantiation. Étude de la pensée de Thomas d'Aquin et de Louis-M. Chauvet

La prière de Jésus et de ses disciples en Luc XXII, 39-46

Une pratique socio-évangélique, une foi éclatée dans la solidarité avec les personnes appauvries

L'approche de la mort dans l'oeuvre d'Élisabeth Kübler-Ross. Présentation et analyse

Le suivi aux sacrements de l'initiation chrétienne chez les jeunes de 9 a 12 ans

Une pratique baptismale renouvelée dans une Église alternative

Pour une morale du compromis 
MONTPETIT, Daniel

M.A. Th. - études bibl.

Pierre LÉTOURNEAU (dir.)
La pédagogie de la foi en Jn 4, 1-42. Regard sur un cheminement de foi à partir des analyses structurelle et argumentative

POTVIN, Jacinthe

M.A. Th. - études bibl. Olivette GENEST (dir.)

Le langage de la croix est-il un langage de sagesse? Analyse sémiotique de 1 Corinthiens 1,173,23

SAINT-MARSEILLE, Alain Job 28 et son contexte M.A. Th. - études bibl. Guy COUTURIER (dir.)

SAINT-MICHEL, Madeleine Habiliter à la présence auprès des M.A. Th. - études past. Jean-M. CHARRON (dir.)

VILLENEUVE, Denis M.A. Th. - études past. Florent VILLENEUVE (dir.) Nicole BOUCHARD (co.dir.) mourants cancéreux à domicile (lecture pastorale d'un geste)

Foi chrétienne à l'heure du pluralisme religieux actuel 